\title{
Le «temps retrouvé» de 1914, sous la direction de Uta FELTEN
}

\section{Ludovico Monaci}

\section{(2) OpenEdition}

\section{Journals}

Édition électronique

URL : http://journals.openedition.org/studifrancesi/15747

DOI : $10.4000 /$ studifrancesi. 15747

ISSN : 2427-5856

\section{Éditeur}

Rosenberg \& Sellier

\section{Édition imprimée}

Date de publication : 1 décembre 2018

Pagination : 524

ISSN : 0039-2944

\section{Référence électronique}

Ludovico Monaci, «Le «temps retrouvé» de 1914, sous la direction de Uta fELTEN », Studi Francesi [En ligne], 186 (LXII | III) | 2018, mis en ligne le 01 janvier 2019, consulté le 06 janvier 2021. URL : http:// journals.openedition.org/studifrancesi/15747 ; DOI : https://doi.org/10.4000/studifrancesi.15747

Ce document a été généré automatiquement le 6 janvier 2021.

\section{(C) $\odot \Theta$}

Studi Francesi è distribuita con Licenza Creative Commons Attribuzione - Non commerciale - Non opere derivate 4.0 Internazionale. 


\title{
Le «temps retrouvé» de 1914, sous la direction de Uta FELTEN
}

\author{
Ludovico Monaci
}

\section{RÉFÉRENCE}

Le «temps retrouvé» de 1914, sous la direction de Uta FELTEN, Paris, Classiques Garnier, 2016, «Revue d'études proustiennes» 3, $130 \mathrm{pp}$.

1 À l'occasion du centième anniversaire du début de la Grande Guerre, les spécialistes proustiens ne pouvaient pas s'abstenir d'analyser l'influence que le premier conflit mondial a exercée sur le destin diégétique de la Recherche: le troisième volume de la collection «Revue d'études proustiennes» réunit les interventions au colloque organisé à l'Université de Leipzig et à l'Institut français de Berlin en 2014.

2 Après la présentation d'Uta FELTEN (Proust archéologue de la Grande Guerre. Quelques réflexions préliminaires, pp.11-14), Luc FRAISSE (L'épisode de la guerre dans "Le temps retrouvé". Une formule romanesque originale, pp.15-39) souligne la nature composite du dernier volume de la Recherche: là, l'auteur et le narrateur s'avèrent être à tour de rôle des mémorialistes, des journalistes, des moralistes et des sociologues. En revanche, la dissertation de Volker Roloff (La guerre dans la perspective de Charlus et du narrateur, pp.41-53) donne un aperçu des métamorphoses des espaces et, surtout, des personnages principaux. Angelika CORBINEAU-HOFFMANN (Militarisme et mémoire dans la "Recherche". Le personnage de Saint-Loup, pp. 55-73) et Michel GRIBENSKI («De notre balcon»: esthétisation de la guerre dans "Le temps retrouvé"?, pp.93-106) se focalisent plus spécifiquement sur Saint-Loup et sur les implications romanesques liées à sa centralité dans le contexte militaire. De son côté, Cécile LEBLAnc (Proust et la musique de temps de guerre. Échos cryptés dans "Le temps retrouvé", pp. 75-91) montre que Marcel Proust connaît et adopte les débats critiques de la presse musicale, sans jamais les plier aux diatribes nationalistes de l'époque. Enfin, le traitement des scènes de guerre dans le film de Raoul Ruiz Le temps retrouvé constitue le cœur de l'étude de Patricia OSTER («Vous 
ne pourriez pas vous figurer». La guerre dans la "Recherche": roman et adaptation cinématographique, pp. 107-125).

3 Bien que la Recherche n'accède jamais aux tranchées et bien que la vulgate nous transmette un Marcel Proust enfermé dans sa tour d'ivoire, cette publication témoigne de l'attention que l'écrivain réservait aux faits de guerre. 